\title{
PRAGMATIC FUNCTIONS OF SWEARWORDS IN THE AMATEUR SUBTITLING OF AMERICAN CRIME DRAMA MOVIES INTO ARABIC
}

\author{
Abed Shahooth Khalaf* \\ College of Education for Humanities, University of Anbar, Anbar, \\ Ramadi, P.O Box 55431, Iraq \\ E-mail: abeeid@yahoo.com
}

\author{
Sabariah Md. Rashid ${ }^{* *}$ \\ Faculty of Modern Languages and Communication, Universiti Putra Malaysia, \\ 43400, UPM Serdang, Selangor, Malaysia \\ E-mail: smrashid@upm.edu.my
}

Published online: 15 January 2019

To cite this article: Khalaf, A. S. and Md. Rashid, S. 2019. Pragmatic functions of swearwords in the amateur subtitling of American crime drama movies into Arabic. International Journal of Asia Pacific Studies 15 (1): 97-131, https://doi.org/10.21315/ ijaps2019.15.1.4

To link to this article: https://doi.org/10.21315/ijaps2019.15.1.4

\begin{abstract}
Swearwords are intentionally employed in movies to express certain pragmatic functions including portraying characters' inner feelings, their social and educational background and the relationship between the characters. Such functions need to be preserved in the interlingual/intercultural subtitling so that the communicative effects of swearwords are duly transferred to the target audience. However, achieving this objective requires a thorough contextual analysis of the relationship between the characters, the intended illocutionary force of the speech acts expressed by the swearwords and the reaction of the addressee to their implied communicative force. A lack of such an analysis may lead to a change in the intended pragmatic functions of swearwords during the subtitling process. In this light, this study sought to investigate the pragmatic functions of swearwords in selected American crime drama movies and their Arabic subtitles, identifying whether the same pragmatic functions of such words have been preserved in the subtitles. The study also attempted to identify the causes and consequences of the resulting (in)congruity between the expressed functions of the swearwords in the movies compared with those expressed by their subtitles in Arabic. To address these objectives, a corpus comprising the scripts of two American crime drama movies exhibiting high occurrences of swearwords and
\end{abstract}


their Arabic amateur subtitles was collated. The pragmatic analysis approach utilising Speech Act Theory was used whereby the primary speech act/force of each swearword was identified, and Wajnryb's (2005) model for categorising the pragmatic functions expressed by the swearwords was employed. The findings of the study indicate significant differences in the expressed pragmatic functions of swearwords in the movies compared to those in the subtitles. As a result, the directors' intentions behind using the swearwords were changed. The main cause of these differences is lack of adequate pragmatic analysis of the uses of swearwords in the movies.

Keywords: Amateur subtitling, pragmatic functions, communicative effect, illocutionary force, Arabic

\section{INTRODUCTION}

The recreation, circulation and consumption of audiovisual products have witnessed great changes with the advent of the digital revolution. One of these changes is the shift in the role of the consumers of such products from passive recipients into active agents in the production and dissemination of audiovisual products. Hence, the term "Prosumers" has been coined to describe the double role of the contemporary consumers of televised and filmic products (Tapscott and Williams 2006). This role has been enhanced by the development of means of communication and the invention of user-friendly and free reproduction apparatus.

An example of the reproduction apparatus is the invention of easy to use subtitling software that has enabled novice subtitlers to actively participate in providing accessible translated versions of televised and filmic products. And with the free access to the Internet, fansubbers (also known as amateur subtitlers) were able to disseminate these subtitles to millions of movie fans worldwide exploiting the file pirating and sharing technology. These amateur subtitlers volunteer to carry out the subtitling of audiovisual products on a free basis to help other fans comprehend the storyline of the movies. They practice the subtitling of movies as a hobby and are stimulated by their affection to help other viewers overcome the language barrier (Lee 2011). According to Bogucki (2009: 49), amateur subtitlers are interested in making "a contribution in an area of particular interest and to popularise it in other countries, making it accessible to a broader range of viewers/readers who belong to different linguistic communities." They represent anonymous figures that exploit the Internet facility to have immediate contact with their audiences and respond to their needs and preferences. Hence, they are said to be more creative and they, thus, represent a revolt against the conventions of 
professional subtitling (Fernandez-Costales 2012; Diaz-Cintas 2005). Their inclination is source text oriented since they adopt foreignisation compared to the domestication approach of professional subtitlers (Venuti 1995). Moreover, amateur subtitling is not geographically restricted and it is provided for almost all movies anytime and everywhere (Orrego-Carmona 2012).

Historically, fansubbing or amateur subtitling is not a new phenomenon. Indeed, it can be traced back to the 1980s with the fansubbing of Japanese anime programmes into English to viewers unfamiliar with Japanese (Diaz-Cintas and Sanchez 2006). Such a subtitling phenomenon gained momentum when professional subtitling was no longer able to keep pace with the increasing demand on audiovisual translation or because it is expensive (Diaz-Cintas 2005). Consequently, thousands of amateur subtitling websites and blogs have been established to provide subtitles for various audiovisual products in different language pairs worldwide (Orrego-Carmona 2015).

However, amateur subtitling is considered illegal; it is an infringement to copyright laws through the pirating of files without license. Amateur subtitlers also seem to lack editing on their subtitling and formal translation training and expertise (Perez-Gonzalez 2012). More importantly, they are said to be of low linguistic and pragmatic competence, which is essential for effective translation of the source text (Bogucki 2009; La Forge and Tonin 2014). Undoubtedly, the outcome of such deficiencies will be apparent on the amateur subtitlers' performance, particularly, when handling the transference of problematic issues, such as the subtitling of swearwords, which are characteristic of spontaneous and informal speech and is meant to make the movie more realistic.

Swearwords represent a reflection of the manipulation of language in different spheres of life by different people to achieve certain pragmatic functions. Among the various functions of swearwords include expressions of anger, frustration, annoyance, surprise, power, solidarity, group membership and happiness, which go beyond the literal meaning of such words (Andersson and Trudgill 1990). Such functions are important for the development of a movie storyline or for characterisation purposes since they reflect the psychological impulses of the characters and their relationship with other characters in the movie. Accordingly, these functions must be preserved in the interlingual/ intercultural subtitling so that the communicative effects of swearwords are duly transferred to the target audience. On this basis, swearwords must, therefore, be accurately handled in the interlingual/intercultural subtitling process. However, the accuracy in handling the pragmatic functions expressed by swearwords to the target recipients requires the subtitler to do a rigorous 
pragmatic analysis of the situational context in which the swearword was used in the movie. This requires a careful analysis of the relationships between characters, the intent of the characters using the swearwords and the reaction of the addressees. Thus, if this is not done, the subtitler's lack of adequate pragmatic competency will be reflected in their inability to maintain the same communicative effect of the swearwords used in the source text in its subtitles.

In relation to this, a number of studies have addressed the issue of (in)congruity in the expressed pragmatic functions of swearwords used in the source text compared to their equivalents in the subtitles (Ameri and Ghazizadeh 2015; Han and Wang 2014; Greenall 2011). However, these studies were mainly confined to professional subtitling, which involved language pairs such as Chinese and English (Han and Wang 2014), Spanish and English (Rodríguez-Medina 2015) but not Arabic. Acknowledging this gap in the literature, this study, therefore, aimed to: (1) investigate the success or failure of the Arab amateur subtitlers in preserving (in)congruity of the pragmatic functions expressed by swearwords in a number of American crime drama movies subtitled into Arabic; and (2) the causes and consequences of the resulting incongruity in preserving the intended communicative effects of swearwords to the audience.

\section{LITERATURE REVIEW}

Since the 2000s, much scholarly work has been directed towards the fansubbing phenomenon (Orrego-Carmona 2015; Díaz-Cintas 2005; Nornes 1999). The focus of the majority of the work conducted in this domain was on the quality of the work done by these subtitlers, the problems they encounter, their working conditions and comparing the performance of professional and amateur subtitlers (Sajna 2013; Wilcock 2013; Bogucki 2009; Diaz-Cintas and Sanchez 2006). Other scholars tended to focus on the translation behaviour of amateur subtitlers when addressing cultural specific issues and the strategies they adopt in the intercultural transference of these issues (García-Manchón 2013; Massidda 2012; Renwick 2012; Tian 2011).

On a different stance, the treatment of swearwords in the amateur subtitling of movies was one of the extensively researched culture specific issues. The finding of most of the studies on this issue was that subtitling swearwords poses a problem to amateur subtitlers; this is why such words were either deleted or toned down in the interlingual transference process. This tendency can be attributed to the offense such words cause to viewers and the variation in the degree of tolerating swearwords across cultures. 
However, the shifts in the intended pragmatic functions expressed by swearwords as a result of the adopted attenuating translation strategies have been less investigated, particularly, within the fansubbing domain. For example, in his study on the subtitling of English movies into Arabic, Mazid (2006: 93) argued that the use of milder swearwords in the subtitles "removes" the overtones of the English swearwords used for certain pragmatic purposes in the movie. Mazid justified this behaviour on the basis that the available colloquial swearwords in Arabic "cannot be written on screen in an Arab culture."

In another study, Hjort (2009) focused on the translation behaviour of subtitlers when handling swearwords and the viewers' reaction towards the treatment of such words. The finding of the study revealed that 66.2 percent of the respondents suggested that swearwords in the subtitles should be of equal strength to those in the original to retain the same communicative effect to the target recipients.

In a similar vein, Bucaria (2009) analysed 12 American television series to identify the behaviour of Italian translators when addressing swearwords. The results of the analysis revealed a general tendency towards censoring swearwords and other objectionable linguistic units, which took the form of complete deletion or toning down the obscenity of such uses. However, such attenuating strategies yielded translations that had lesser impact on the Italian audience, particularly, when it comes to rendering humour into the target audience.

Using a corpus-based approach, Lie (2013) studied the Norwegian subtitling of swearwords in 15 English movies. A quantitative analysis of the semantic, syntactic and functional mismatches between these words and their subtitled counterparts was carried out on the subtitles in Norwegian. In discussing the findings of the study, Lie affirmed that the Norwegian subtitles preserved the functions of swearwords although the structures, denotative meaning and connotative strength were different.

Similarly, Han and Wang (2014) attempted to explore two aspects in the subtitling of English swearwords in eight episodes of the reality TV series The Family into Chinese. The first was whether there was a disparity in the semantic categories and pragmatic functions of swearwords in the English scripts and their Chinese subtitles. The second pertained to the translation strategies adopted in rendering English swearwords into Chinese. The overall findings of the study revealed a tendency to mildly tone down the force of swearing in the subtitling process, yet the communicative functions and offensive force were, by and large, retained via the use of certain translation 
techniques. As for the functions of swearwords, the analysis revealed a decrease in the number of these functions in the subtitles in comparison with the original text. Such a tendency resulted in downgrading the intensity of the swearwords in the subtitles.

Moreover, Ameri and Ghazizadeh (2015) compared the translation behaviour of professional dubbers and nonprofessional subtitlers in their treatment of swearwords in the English movie Pulp Fiction (1994) into Persian. The analysis of the data revealed certain translation strategies which were adopted by both translation groups including direct translation with strong force of swearwords and direct translation with weak force of swearwords. However, while professional dubbers adopted a target culture orientation, the amateur subtitlers adopted a source text-oriented approach, thus, producing a translation that had succeeded in preserving the style of the source text. This shows that professional dubbers were abiding by cultural norms in the target culture more than amateur subtitlers.

As the previous account of the scholarly work carried out on the subtitling of swearwords in movies shows, the majority of the previously surveyed studies seemed to have focused mainly on the professional subtitling, whereas the amateur subtitling of swearwords was not given due attention. Therefore, the present study attempts a contribution to fill up this gap in the literature by focusing on the Arab amateur subtitlers' translation behaviour with respect to identifying whether the same pragmatic functions of swearwords in the movies have been preserved in the subtitles and the causes and consequences of the resulting shifts of the functions of swearwords in the subtitles.

\section{PRAGMATIC IMPLICATIONS IN INTERLINGUAL SUBTITLING}

As generally acknowledged, swearwords are used to achieve various pragmatic functions. Hence, a sound understanding of the pragmatic functions of swearwords should be based on the implications of pragmatics in determining the intended meaning of utterances. Generally speaking, pragmatics is seen as complementary to semantics as both deal with meaning. However, while the latter is concerned with meaning as perceived from the truth conditions of utterances, the former deals with cases in language use where more is being communicated than is actually stated. It focuses on language use from the perspective of the users engaged in an act of communication. Within this perspective, the use of language is purposeful, i.e., in any act of communication, speakers intend to achieve particular ends. Hence, meaning as use implies speakers' intention to communicate a special 
effect by the utterances. Of significance for the success in determining meaning in interaction is an understanding of the context of situation of what is said and its influence on the interpretation of utterances. The notion of context encompasses elements of the when, where, under what conditions and who the speaker is addressing. Thus, meaning is determined by considering the interaction of these contextual elements, which may yield different interpretations of an utterance in different sociocultural contexts. This variation in interpreting utterances across different sociocultural settings is responsible for the disparity in conveying the communicative effect of swearwords in interlingual/intercultural communication.

Accordingly, since communicating the expressive functionality is the most important when handling swearwords, it seems useful to study them under the realm of Speech Act Theory. Introduced by Austin (1962), this theory construes speakers' utterances as performing certain acts. The theory attempts to analyse these utterances by relating them to the behaviour of the speaker and the addressee engaged in interpersonal communicative acts. Hence, the speech act of an utterance represents a communicative activity reflecting the speaker's intention and the effect he intends to achieve on the addressee.

In interlingual subtitling, knowledge of the implications of this theory is useful to arrive at an understanding of various constructs in language use where meaning cannot be decided via the propositional content of speech exchanges. Emphasising this notion, Mubenga (2010: 268) argues that "interlingual subtitling is made easier if subtitlers consider the subtitles as corresponding to the speech functions or speech acts that occur in the film discourse." Related to this, Gottlieb (1998: 247), affirms that the focus in subtitling should be the speech act of the utterance. This is true because the speaker's intention and the effects he wants to communicate "are more important than isolated lexical elements."

According to Speech Act Theory, upon the articulation of an utterance (locution), the speaker is achieving a simultaneous act known as the illocutionary force of the utterance which intends to affect the addressee to behave in a particular manner (the perlocutionary force). Out of these forces, the illocutionary is the most important since it represents the effect the speaker intends to achieve through producing the utterance. According to Pedersen (2008), the same speaker may send two illocutionary forces encapsulated in a single indirect speech act. These the author designates as primary and secondary forces/points. Since the primary illocutionary point pertains mainly to the non-literal meaning of utterances (Verschueren 1999), it is this force that should be retained in the interligual subtitling of swearwords. It is usually seen as a communicative act within the framework of a sociocultural 
dimension. Speakers within a speech community grasp the illocutionary force of utterances depending on their schemata or shared background knowledge with the members of their speech community (Cutting 2002). In cases of "misprocessing," pragmatic failure ensues as a result of identifying unintended forces or relegating intended ones (James 1998).

From a linguistic perspective, House (1981) argues that two elements can be utilised to identify the illocutionary force of utterances namely, grammatical features (including stress and intonation) and context. For Searle (1976), the contextual devices to identify illocutionary forces are called illocutionary force indicating devices (IFID). Accordingly, if a subtitler succeeds in identifying and rendering the primary illocutionary force/point of the source text in the subtitles, his translation will be highly felicitous. However, if only the secondary illocutionary point is rendered, the subtitler's translation is less felicitous, and if none of these points is rendered, the translation is erroneous or infelicitous (Pedersen 2008).

From the perspective of Functional Grammar, the negotiation process of the intended meaning of utterances or their illocutionary force points to the "interpersonal metafunction" of language (Halliday 2004: 29). This function of language proposes that the type of language which speakers use reflects their positive or negative attitudes towards their addressees. It is a reflection of the social relationship between interlocutors in terms of their social distance, their degree of intimacy, power and solidarity.

\section{INTERLINGUAL SUBTITLING AND ITS CONSTRAINTS}

Interlingual subtitling is a communicative activity aiming at assisting foreign audiences unfamiliar with the language used in the film or TV programme to comprehend its dialogue and follow the developments of the storyline. According to Diaz-Cintas and Remael (2007: 8), subtitling is defined as a:

translation practice that consists of presenting a written text, generally on the lower part of the screen, that endeavors to recount the original dialogue of the speakers, as well as the discursive elements that appear in the image [...], and the information that is contained on the soundtrack $[\ldots]$.

In comparison with dubbing and voice-over, interlingual subtitling implies two shifts in language medium; one from the spoken mode in the source text to the written mode in the target text and another from the language used in 
the movie to another language in the subtitles. This compound process makes interlingual subtitling "diagonal" and "diasemiotic" (subtitling "crosses over from writing to speech, or from speech to writing") (Gottlieb 2004: 219), while dubbing and voice-over are "isosemiotic" since they are carried out in the same mode (using the same semiotic channel as the original, i.e., rendering speech as speech and writing as writing) (Gottlieb 2001: 17).

The shift from the spoken to the written mode entails the eradication of most of the "redundant" elements characteristic of face to face interactions such as repetitions, intonation, slang language and swearwords among others. This need for reduction in subtitling is necessitated by the technical (spatial and temporal) constraints characteristic of the medium. As for the spatial constraint, the number of lines to appear on the screen should not exceed two per subtitle with a total of (35-40) characters per line (Ivarsson and Carroll 1998). Such a limitation is necessary in order not to occupy a big portion of the small TV screen and disturb the viewer's enjoyment from watching the images. This temporal constraint stems from the synchronisation that should be achieved between the actors' utterances and the added subtitles. In this case, care should be taken to regulate the in and out timings of the subtitles with the moment an actor begins and finishes his utterance. Unless a harmony is accomplished, confusion may ensue resulting in an overlap between the turn shifts and the imposed subtitles. To reiterate, the subtitles may either appear before an actor starts speaking or remain longer than necessary whereby another actor starts speaking, making the viewer unable to identify the speaker and the corresponding subtitles. In relation to this, Ivarsson and Carroll (1998) suggest that the amount of time for subtitles to remain on the screen should not be less than 1.30 seconds and it should not exceed 6 seconds depending on the number of lines in each subtitle.

Another characteristic of interlingual subtitling is the concurrency between the spoken language in the source text and the added subtitles in the target language. This represents another restrictive factor for the subtitler because even the ordinary viewer with reasonable knowledge of the movie's language will be able to judge the quality of the subtitling (Gottlieb 2001). Dubbing and voice-over, on the other hand, "hide" the original sound track, hence giving the translator more freedom to edit the translation and tailor it in such a way as to make it conform to the viewers' "expectations" (Chesterman 1997). Nevertheless, keeping the original sound track intact renders subtitling more authentic in comparison with dubbing and voice over as it maintains the sense of otherness which is an essential objective of watching foreign movies. 
The characteristics of interlingual subtitling entail the fact that subtitlers work under different competing physical, technical, linguistic and cultural forces. Such forces are a normal consequence of the multimodality of the movie texture, whereby the auditory, visual, verbal and non-verbal channels of communication jointly work to convey the intended message in the movie in an effective manner. In the movie setting, even the characters' body movements and their gestures become communicative and socially interactive. They are designed to "function like illocutionary force markers" to accomplish a "discourse functionality," which "the speaker feels to be important with respect to the larger context" in which he is engaged (McNeill 2006: 4). Hence, such body movements and gestures assist the speaker in conveying his intended message since they could be meaningful without the need to speak. However, they would either facilitate or hinder the interlingual subtitler's task to convey the intended meaning as not all of them can be transferred into orthographic symbols, which are, therefore, left to the viewers to interpret by association with the movements of the characters using them. This state of affairs led scholars to describe interlingual subtitling as a "constrained translation" (Titford 1982), or as an act of adaptation.

\section{THE MOVIES}

In total, two American movies were selected to represent the corpus of the study. A brief account of each movie is given as follows.

\section{Alpha Dog (2006) (hereafter referred to as AD)}

Alpha Dog, directed by Nick Cassavetes, is rated as " $R$ " (age limit 17 years) because it portrays drug use, strong violence, sexuality and nudity. The movie narrates the story of the murder of a 15-year-old teenager, Zack, by a group of drug dealers because Jake, Zack's half-brother, was not able to repay Johnny, the head of the group, a drug debt of $\$ 1,200$. As a result, the latter kidnapped Jake's half-brother as a ransom. Fearing of being sent to jail or killed if the kidnapping of the boy is discovered, Johnny decided to kill Zack. Throughout the development of the story, many friendly and unfriendly confrontations between members of the gangs ensue. These instances of confrontation represent a good depiction of the atmosphere in the movie and instigate characters to use swearwords of all types. Hence, the use of swearwords is intentionally deployed to accomplish certain pragmatic functions and to portray the relationships between the characters in the movie. 


\section{Harsh Times (2005) (hereafter referred to as HT)}

Harsh Times, directed by Davis Ayer, is also rated R (age limit to 17 years) due to the violence, bloodshed and sexual references it portrays. The movie depicts the struggle of a former United States army ranger, Jim and his close friend, Mike, in their failed attempts to get jobs for a better living. The movie is built on flashbacks as a dramatic technique to reflect the psychological state of Jim who suffers from a post-traumatic stress disorder. The impact of this disorder has been so influential in shaping Jim's behaviours. The movie portrays the behaviours of the main characters in several conflictive and confrontational scenes. These confrontational scenes push characters to resort to the use of various types of swearwords to express various emotional impulses. The movie ends with a bloody scene that shows Jim and Mike in dispute with a group of gangs. The struggle develops into shooting where Jim, triggered by his disorder, kills all gangs. While attempting to run away, a man from the neighbourhood shoots Jim in the back and the face. Jim becomes paralysed and urges Mike to shoot him and end his sufferings. The final scene shows Mike shooting Jim dead.

Like the first movie, HT portrays high use of swearwords by the different characters in the movie, which reflect the inner feelings of these characters, their social class and the relationships amongst them.

\section{METHODOLOGY}

In any study, it is imperative to clearly define any concept or term as used in the study. In this study, the term "swearword" is used as defined by Andersson and Trudgill (1990: 53) as a type of language that:

1. refers to something that is taboo and/or stigmatised in the culture;

2. should not be interpreted literally; and

3. can be used to express strong emotions and attitudes.

Accordingly, swearwords fulfilling this definition in the movies were extracted for inclusion in the data. Each of the identified swearwords and its counterpart in the Arabic subtitles are underlined in the results and discussion section. A literal back translation of the Arabic subtitles is also provided with a transliteration to help non-native speakers of Arabic to read and understand these subtitles. In the transliteration, the phonological transcriptions of the Arabic words were adopted from the transliteration system of Dewan Bahasa dan Pustaka (2008). 


\section{Research Approach and Data of the Study}

This study, which is qualitative in nature, adopted a corpus-based analysis approach to examine whether the same identified pragmatic functions of swearwords expressed in the movies have been preserved in the subtitles or not. The data of the study comprised a corpus consisting of the scripts of two American crime drama movies, namely, AD (2006) and HT (2005) and their amateur subtitles in Arabic with a total number of 73,328 words.

The crime drama genre is a suitable source for a study on pragmatic functions of swearwords in subtitling since this genre depicts the deployment of language by speakers, such as criminals, gangs and drug dealers in their daily interactions. The frequent use of swearwords reflects certain pragmatic purposes, such as venting anger, frustration or showing solidarity or power. According to Parini (2013: 154), the use of all types of swearwords has become "more common in a recent stream of American films, such as spy, mafia and gangsters films, films starring drug addicts and dealers, prostitutes, homeless people, soldiers, convicts, warders and policemen." Moreover, the deployment of swearing, violence and sexual explicitness has become "part of the DNA" of American audiovisual products (Bucaria 2009: 16). Affirming the same idea, Rodríguez-Medina (2015: 2) believes that "there is a high frequency of dysphemisms in American crime films." This excessive use of swearwords represents a translation problem particularly for amateur subtitlers with less linguistic and pragmatic competence and less formal translation training. These subtitlers should pay careful attention to the language used by characters since people are central elements in crime dramas. Hence, all features of the language characters use "from vocabulary to accent, are fundamental to the construction of the characters" (Guardini 1998: 97). This assumption is shared by Casarini (2014: 10), who argues that such a type of literary genre focuses on character types and their sociolects whose preservation in the target text represents a challenge to the translators "who need to deal with the genre's intrinsic self-referential dynamics and with a mercurial language that can rarely have perfect interlinguistic equivalents."

As for the data source, the selected movies have the highest number of swearwords within this genre for a period between 2000 and 2010. The high occurrence of swearwords in the selected movies was confirmed by consulting sources such as Moad's (2011) list of movies with the most audible uses of the word "fuck." The list referred to above ranks the most offensive movies on the basis of the instances of the word "fuck" in each of them. In addition, the selected movies cover a period extending from 2000 to 2010 to 
coincide with the widespread use of the Internet facility in the Arab World and the formation of amateur subtitling websites in this region (Gamal 2008). Furthermore, academic interest in non-professional subtitling and the place it occupied in translation studies began in 2000 (Orrego-Carmona 2014, 2015). Moreover, according to Casarini (2014: 26), peer-to-peer media file sharing through the Internet service started operating "between June 1999 and July 2001 and allowed users to exchange media files." The selected movies are also popular and can be downloaded from the Internet; hence, viewers are most likely to access these movies. In line with this, the dialogue scripts were downloaded from the website http://www.opensubtitles.org/en/search, while the subtitles in Arabic were downloaded from http://www.subscenes.com. This is necessary to ensure that the downloaded subtitles were those done by amateur subtitlers. In addition, the selected movies are American movies as they were produced in Hollywood. Hence, according to Gamal (2008), most of the imported movies to the Arab World are Hollywood American movies. To ensure that the movies have been widely watched in the Arab World, the number of downloads of their subtitles was checked (16.824 [AD] and 14.658 [HT]) depending on the above website.

\section{Data Identification and Selection}

Data identification and selection involved a series of meticulous processes. The identification of the pragmatic functions of swearwords in each movie first required watching each movie separately whilst at the same time identifying the pragmatic functions on a hard copy of its dialogue scripts. The movie was then played several times and each shot exhibiting an occurrence of swearwords was spotted. This involved frequent pausing, playing back and forwarding to accurately determine the pragmatic function of the used swearword. Deciding on the pragmatic function of swearwords was also based on a rigorous pragmatic analysis of the contextual factors triggering the use of the swearword. Of particular significance is the relationship between the interlocutors engaged in the speech exchange, their body movements and facial expressions as well as the intention of the speaker uttering the swearword (illocutionary force) and the reaction of the addressee towards the uttered swearword (perlocutionary force). The tone of voice and other prosodic features in the movie also played a significant role in this regard. The identified pragmatic functions expressed by the swearwords in the movies were compared to those expressed by the rendered swearwords in the subtitles. On the basis of contrasting the pragmatic functions of the swearwords in both sub-corpora, (in)congruities in this regard were identified. 


\section{Data Analysis}

Pragmatic analysis utilising Speech Act Theory (Austin 1962) through contrasting speech acts in the source text and the target text was used in the analysis of the expressed pragmatic functions of swearwords in both corpora. The adoption of pragmatic analysis was useful in achieving the objectives of this study since, according to Yule (1996: 3), within pragmatics "a great deal of what is unsaid is recognised as what is communicated." More importantly, pragmatics studies meaning in context, which "requires a consideration of how speakers organise what they want to say in accordance with who they are talking to, where, when and under what circumstances" (Yule 1996: 3). Thus, pragmatic analysis is deemed appropriate for what is focused on in the analysis of the expressed pragmatic functions of swearwords used in the movies.

To better verify the identified pragmatic functions of swearwords, a verification procedure for the analysis of the pragmatic functions of swearwords in the corpus was also carried out. For this purpose, two native speakers of English and two native speakers of Arabic participated in this procedure as raters. The Arab participants hold an MA degree in English language and linguistics and have taken courses in pragmatics, which is a necessary condition to answer the verification sheet. Specifically, each rater was given a $C D$ of the movies and a copy of the verification sheet which comprises excerpts containing instances of swearwords extracted from different parts of each movie. The raters were asked to determine the pragmatic functions of the swearwords used in each excerpt while watching the movie. The time frame of these excerpts was identified to facilitate the raters' task. Moreover, a brief description of Wajnryb's (2005) model was also provided to familiarise the raters with the criteria to be used in allocating each swearword into a particular category depending on the primary speech act the swearword is intended to express.

As for the analysis of the swearwords according to their pragmatic functions in both corpora, Wajnryb's (2005) model was adopted in categorising the swearwords into the pragmatic function expressed by each swearword. The rationale behind using this model is that its categorisation is broad yet economical since it consists of only three categories. It takes into account the uses of swearwords within their context of situation and its applicability is not confined to a particular language and is user friendly. According to this model, swearwords are used to express three main functions; cathartic, abusive and social. These three functions can be summarised as follows: 
1. Cathartic: this function of swearwords comes in the form of a response to a sudden and unfavourable event that impinges on the individual's course of actions. It usually expresses psychological emotions such as anger, pain, frustration and the like. Thus, it is normally directed at the speaker him/herself and the attendance of other people is not necessary, though it might be directed at other things causing the pain. It is considered a healthy behaviour as it works to restore the individual's psychological equilibrium and lowers stress levels.

2. Abusive: it is the planned and venomous function of swearwords which is mainly directed at others with the intent to insult. Hence, the attendance of a target is necessary, yet it is used as a verbal aggression to replace physical attack.

3. Social: it is interpersonal and used among homogeneous groups of speakers within the same speech community during periods when they feel at ease. Though directed at others, it is neither venomous nor intended to hurt. Rather the intent is social solidarity, banter and group membership. It commonly appears in informal interactions to kill the routine and cheer up speech. The social class, gender and age of interlocutors have certain influence on the use of social swearing (Wajnryb 2005: 30-35).

4. These functions of swearwords share interesting features. On the one hand, the cathartic group shares the non-venomous characteristic with the social group. On the other, the abusive group shares the necessity of having a target with the social group.

\section{RESULTS AND DISCUSSION}

Figure 1 presents the results of the analysis of the pragmatic functions of swearwords in both corpora based on the adopted model of Wajnryb (2005). 


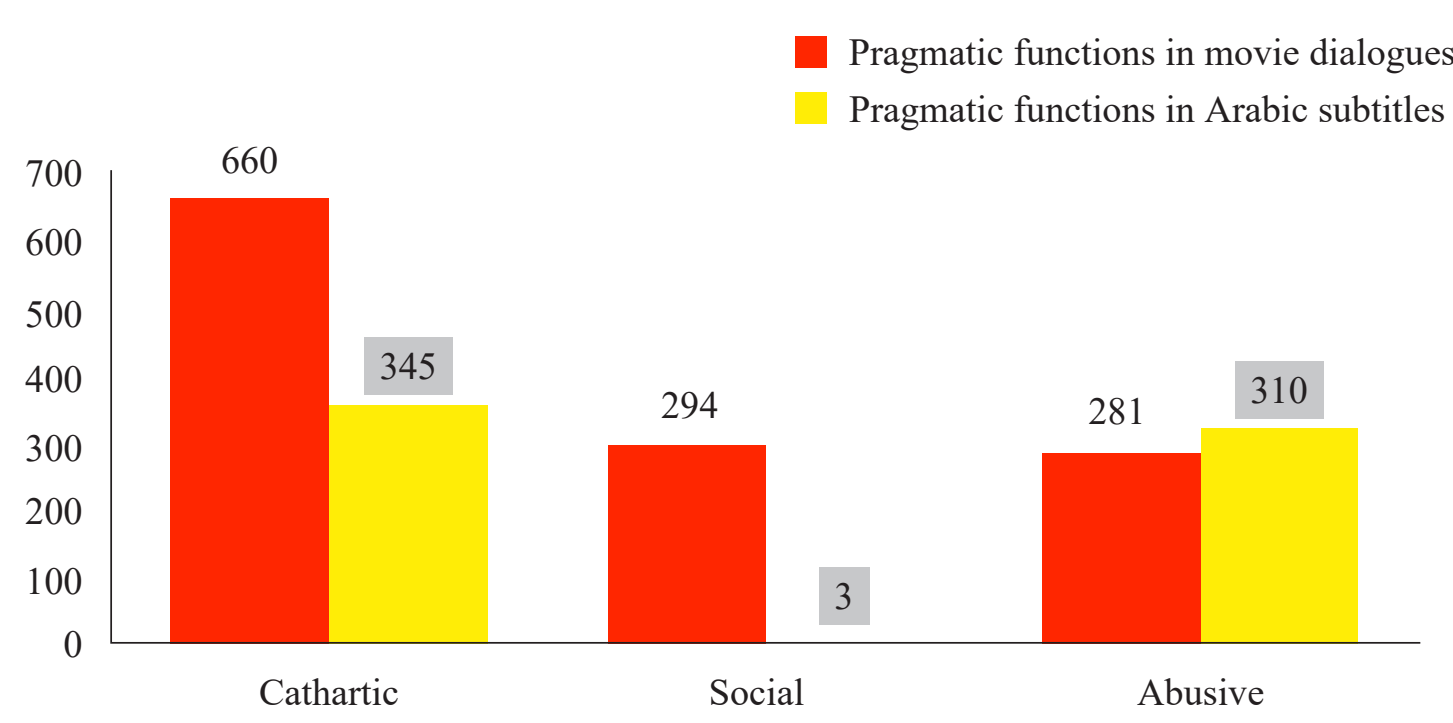

Figure 1: Distribution of pragmatic functions of swearwords in English and Arabic corpora.

As Figure 1 shows, there are notable differences in the number of functions expressed by swearwords in the English movie dialogues and those of the Arabic subtitles. Specifically, fewer functions expressed by swearwords in the movies were converted into the Arabic subtitles. This indicates shifts or losses of functions of swearwords in the subtitles. The analysis revealed that only about half of the cathartic functions in the source texts (660) were preserved in the subtitles (345), and that the social functions expressed by swearwords in the source texts (294) were almost completely removed from the Arabic subtitles (3) while the abusive functions were higher in the target text (310) than their counterparts in the source texts (281) as they were increased by a change in other pragmatic functions to the abusive category. The causes and consequences of such incongruity in the identified pragmatic functions of swearwords in both corpora are highlighted in the following analysis and discussion of each pragmatic category after a presentation of the patterns for rendering the pragmatic functions of the expressed swearwords in the subtitles is given in Table 1. 
Table 1: Patterns of rendering pragmatic functions in subtitling.

\begin{tabular}{lllr}
\hline No. $\begin{array}{l}\text { Pragmatic functions of } \\
\text { swearwords in ST }\end{array}$ & Pragmatic functions in subtitles (TT) & Freq. \\
\hline 1. & Cathartic & 1. $\quad \begin{array}{l}\text { Maintaining cathartic functions in subtitles } \\
\text { (including catharsis with less swearing force) }\end{array}$ & 269 \\
& 2. Changing catharsis to abusive & 51 \\
2. Social & 1. Changing social functions to abusive & 97 \\
& 2. Changing social functions to cathartic & 50 \\
& 3. Maintaining social function in subtitles & 3 \\
3. Abusive & 1. Abusive maintained abusive & 162 \\
& 2. Changing abusive to cathartic & 26 \\
\hline
\end{tabular}

As shown in Table 1, many of the pragmatic functions expressed by the swearwords in the source texts were changed in the rendered swearwords in the subtitles. For instance, several cathartic functions were changed to abusive functions and several abusive functions were changed to cathartic functions in the subtitles. However, the greatest changes were from the social pragmatic functions in the source texts to the abusive in the subtitles as discussed below.

\section{The Cathartic Functions of Swearwords in the Corpus}

The cathartic pragmatic functions expressed by the swearwords were used most in the English sub-corpus of the study. They constituted 53.44 percent out of the total number of the identified pragmatic functions. This high percentage did not come as a surprise as it is in line with the general atmosphere depicted in the movies. That is to say, since characters often came in conflictive and hotly debated situations with each other, they tended to use swearwords with such functions to express their reactions in such situations. For that purpose, different swearwords were employed to express various inner and psychological feelings such as frustration, dismay, annoyance, anger, shock, surprise, happiness and joy. A similar finding was arrived at by Ameri and Ghazizadeh (2015) in their study on the rendition of pragmatic functions of swearwords in the English movie Pulp Fiction into Persian.

As for the identified cathartic functions in the Arabic subtitles in the current study, the analysis revealed a tendency which maintains the same dominance and use of the cathartic pragmatic functions of swearwords. However, three translation patterns were identified in the analysis of the treatment of the cathartic functions in the Arabic subtitles, as shown in Table 1 above. The analysis shows that either the same cathartic pragmatic functions of swearwords were maintained, rendered with less cathartic swearing 
communicative effect or changed to abusive pragmatic functions. Moreover, there were several shifts to the cathartic category mainly from the social pragmatic category and to a less extent from the abusive pragmatic category. These shifts are explained in the following subsections with typical illustrative examples.

\section{Maintaining similar cathartic functions of swearwords in the subtitles}

The first pattern (Table 1) of treating the cathartic functions expressed by the swearwords in the movies portrays instances in which the same illocutionary force of the cathartic pragmatic functions of the swearwords used in the movie dialogue was conveyed to the recipients. In this way, faithfulness to the source text was achieved whereby the target text's recipients were brought very close to the depicted atmosphere intended by the directors and the translation is thus highly felicitous (Pedersen 2008). Examples 1 and 2 illustrate this point.

Example $1(\mathrm{HT})$ :

I don't believe this shit, Letty...

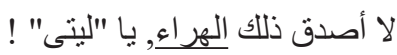

(lā ūṣaddiqu dhālika al-hurā', ya liti) (Lit. I do not believe this nonsense, Letty.)

In example 1, Jim used the swearword "shit" to express the primary illocutionary forces of surprise, anger and frustration of his girlfriend, Letty, who was telling him that she was making out with her new boyfriend. The change in Letty's relationship with Jim was caused by the latter's bad temper, which was a result of a post-traumatic stress disorder. These same cathartic impulses were successfully conveyed in the subtitles by the use of the swearword hura in Arabic, [Lit. nonsense], which coincides with its English counterpart in the source text in expressing these nuances of meaning. However, the Arabic equivalent swearword is from the abuses and absurdities semantic field, which is different from that in the source text being from the body excrement semantic field. Hence, the filth and coarseness implied in the word "shit" were lost in its Arabic counterpart. This shift in the semantic fields of swearwords in the source and target texts was a result of the shift from the spoken, informal and colloquial discourse in the movie dialogue to Standard Arabic in the written subtitles. Usually, colloquial Arabic is spoken but not written and cannot be used in media and educational institutions. However, despite this shift, almost the same communicative effect was maintained in the subtitles as intended in the movie dialogues, making the translation highly felicitous (Pedersen 2008). Example 2 further illustrates this notion. 
Example $2(\mathrm{AD})$ :

What the hell is he still doing here?

مـا الجحيم الذي يبقيه هنا الآن؟

(ma l- jahīim al-ladhī yubqīhi hunā al-ā’n) (Lit. What is the hell that keeps him here now?)

In example 2, the word "hell" was cathartically used by Susan, Frank's girlfriend, when she saw that Zack, the kidnapped small boy, was not returned home. She was feeling pity for Zack and urged Frank to send him back home. Frank promised her to end the kidnapping and release the boy. When Susan discovered that Zack was not released, she used the swearword "hell" in the source text to express the primary illocutionary forces of anger and frustration. Keeping the same functions in the subtitles, the word jahim [hell], which is from the same religious semantic field as that of the source text, was used. Accordingly, by opting for an almost literal equivalence, the same cathartic force was maintained in the subtitles. Interestingly, the word jahim in Arabic, as the word "hell" in English, is an expletive which is mainly used for cathartic purposes to vent inner feelings similar to those expressed in the above example.

\section{Expressing catharsis with less swearing force in the subtitles}

The second translation pattern (Table 1) implies the use of swearwords of a less cathartic force in the subtitles compared to those in the dialogue scripts. That is to say, although the pragmatic function of swearwords in the movie was accurately identified, i.e., as being cathartic, the equivalents provided do not convey the exact intended illocutionary force as examples 3 and 4 illustrate.

Example 3 (AD):

Do you see the fucking moon, Elvis?

هل ترى القمر اللعين با (الفيس) ؟

(hal tarā al-qamar al- la'īn' yā alvis) (Lit. Do you see the damned moon, Elvis?)

In example 3, the source text contains the swearword "fucking," which was used by Johnny to address his friend Elvis who was perceived by his friends as being ignorant. In this scene in the movie, Elvis was suggesting to go out because it was hot inside, but Johnny was ridiculing this idea since it was very late at night. Here, the swearword was primarily used to intensify the illocutionary forces of dismay and anger of the speaker (Ljung 2009). In the subtitles, an approximate illocutionary force was maintained, though with the use of a swearword $l a$ ' $\bar{\imath}$ [damned] from a different (religious) semantic field 
with a less swearing intensity compared to that in the source text. Among the functions of the Arabic swearword la' $\bar{i} n$ is to express anger and frustration, hence its use in this context in the movie coincides with that of the English swearword "fucking" although with a less communicative force since the sexual overtones are missing from the Arabic swearword la'in. As stated in example 1, the shift in the semantic field of the Arabic equivalent swearword in the subtitles is necessitated by the change from the informal colloquial variety of English in the movies to Standard Arabic in the subtitles. Hence, in this case, the use of a Standard Arabic (religious) swearword could be due to its more "prestigious" status and lesser emotive overtones than the direct and colloquial counterpart (Al-Khatib 1995). Example 4 further illustrates this notion.

Example 4 (HT):

Shit, they're gonna love me.

اللعنة, لسوف يحبونني

(al-la'nah, la sawfa yuhibūnanī) (Lit. Damn, they will like me.)

In example 4, the swearword "shit" was used by Jim when he was asserting to his friend Mike that the Los Anglos Police Department would appreciate his military experience and recruit him. The swearword was cathartically used as an expletive interjection in this context to express the primary illocutionary forces of annoyance and dismay. In the Arabic subtitles, this function was expressed by the religious word al-la'nah [damn]. However, the force of the swearing instance in the subtitles tended to be lesser than that in the source text as a result of using a word which is devoid of the coarseness and obscenity of its equivalent in the source text. This observation is in conformity with that of Han and Wang's (2014) study on the subtitling of swearwords in English reality TV series into Chinese. In their findings, the authors argued that the subtitlers were able to retain the pragmatic functions of swearwords in the English texts when subtitled into Chinese although "the force of swearing is downgraded in the Chinese subtitles, since they do not fully reflect the coarseness of the English original." (Han and Wang 2014: 8). The authors attributed the decrease in the swearing force to the selection of swearwords in the target texts, which lack the obscenity, filth and coarseness of the original. The same thing happened in example 4 , which is a result of selecting a counterpart in the target text from a different semantic field due to the shift from the informal English discourse in the movies to Standard Arabic in the 
subtitles. Hence, the religious swearword al-la'nah carries less offense and coarseness than its English counterpart "shit" from the semantic field of body excrement, which in turn, will not convey the same meaning and reflect the same emotions to the audience.

\section{Shift from cathartic functions in the source text to abusive functions in the target text}

A third pattern (Table 1) in transferring the cathartic pragmatic functions expressed by swearwords used in the movies when subtitling into Arabic was to change them into expressions with abusive pragmatic functions. In this manner, the swearing force was upgraded and became stronger than intended in the source texts. Consider examples 5 and 6 below.

Example $5(\mathrm{AD})$ :

What's the matter?

You don't answer a motherfucking page?
ما الأمر ـ لما لا تجيب على هاتفاك أيها السافل (ma l-amr, lima lā tujībū a'lā hātifika ayyuhā ssāfil) (Lit. What is the matter? Why do not you answer your phone, you_villain?)

In example 5, the swearword "motherfucking" was used by Johnny while on a phone call with Jake asking him for money. In this context, Jake took money from Johnny to buy drugs and was unable to return his money. In several occasions, Johnny was urging him to pay back the money and became annoyed when Jack stopped answering his calls. In this case, the speaker's primary use of the swearword "motherfucking" was not meant to be abusive as it was not directed at the addressee. Rather, it was used as a means of venting his anger and frustration towards the indifference of the addressee. In the subtitles, on the other hand, the speaker was portrayed as throwing a direct abusive insult at the addressee. This was achieved by the phrase ayyuhā ssäfil [Lit. You villain], consisting of the vocative "you" and the swearword "villain," forming an epithet that disparages the addressee. Accordingly, by opting for this swearing expression ayyuhā ssäfil [Lit. You villain], the intended primary illocutionary force of the swearword was changed in the subtitles. This has resulted in an inaccurate transfer of the source text's illocutionary force due to the inability to correctly identify this force (James 1998). This shift is further illustrated by example 6 . 
Example $6(\mathrm{HT})$ :

You fucked up, woman.

أنت مجنونة يا إمرأة !!

(anti majnūnatun yā mmra'ah)

(Lit. You are mad, woman!)

In example 6, the formulaic expression "fucked up" was used by Jim when addressing his Mexican American girlfriend, Marta, who refused to make love with him because she was pregnant. Jim did not want Marta to be pregnant, and when she told him the truth, he became annoyed and uttered this swearing expression. This expression was used to express the primary illocutionary force of the speaker's annoyance caused by the mistake made by the addressee. In the subtitles, however, the use of the phrase anti majnunatun [Lit. You are mad], served as a direct abusive insult to the woman, i.e., attacking her mental ability. The use of the vocative particle anti [you/female] and the insult majnunatun [mad], has ascertained the abusive status of the swearword in the target text. Consequently, the intended primary cathartic function of the swearword in the source text was changed into an abusive one in the subtitles.

The incongruity of the pragmatic functions expressed by swearwords in both source texts and target texts stems from the way these words are perceived by both cultures when used in exchanges. In the English spoken discourse among gangs, for instance, "motherfucking" is conceived as a way of talking to emphasise the word it proceeds. In this case, it is seen as a "slot filler" (Ljung 2009) that assists in conveying the intended illocutionary force. In Arabic, on the other hand, the word säfil [villain, of low status], is pejorative and is meant to insult the addressee. Moreover, while the idiomatic swearing expression "fucked up" is used to criticise an act as being careless or incorrect, the word majnūn [mad, crazy] in Arabic is merely used as highly insulting. In the above examples, the shifts in the employed swearwords also resulted in the shift of the intended pragmatic functions of swearing instances, and thus the subtitles appeared ruder and more offensive to the Arab audiences (Zauberga 1994). This is actually true since the Arab audience does not accept insulting swearwords in public exposition with the same ease as English viewers do. On this basis, the increase in the degree of offensiveness rapidly saturates the Arabic subtitles and raises the objection level on the part of the audience. Moreover, it contributes to masking the depiction of the relationship between characters in the movie (Kovacic 1995). 


\title{
The Social Functions of Swearwords
}

The social pragmatic functions expressed by swearwords ranked the second in terms of frequency in the English sub-corpus of the study (Figure 1). They constituted 23.80 percent out of the total number of the identified pragmatic functions in this corpus. Within the social function category, the majority of the social pragmatic functions of swearwords in the movies were changed to either abusive or cathartic functions as shown in Table 1. These changes are discussed in the following subsections with illustrative examples.

\section{Shift from social functions in the source texts to abusive functions in the target texts}

The shift from the social to the abusive functions suggests "misprocessing" of the intended social pragmatic functions of swearwords used in the movie dialogues and skewing them into abusive functions in the subtitles. The skewing process was accomplished by choosing a swearword in Arabic which is perceived by the Arab audience as insulting or disparaging, resulting in a harsher depiction of the movie atmosphere. Hence, the friendly and intimate moments in the movies were changed into conflictive and confrontational ones in the subtitles. This shift, however, conveys an inaccurate portrayal of the relationship between characters in the movie as a result of lack of a keen pragmatic analysis of the source texts. Examples 7 and 8 illustrate this shift.

Example $7(\mathrm{AD})$ :

Did you hear me, you fucking fruitcake?

\author{
هل تسمني أيها الأحمق \\ (hal tasma'unī ayyuhā l-aḥmaq) \\ (Lit. Do you hear me, you idiot?)
}

In example 7, the swearwords "fucking fruitcake" were used by an old man addressing Johnny. According to the Online Urban Dictionary, the word "fruitcake" is derogatory as it indicates a homosexual or completely insane man. In combination with the premodifier intensifier swearword "fucking," these two swearwords can be very offensive. However, in this context in the movie, they were used to express a social function, i.e., a sign of endearment by the speaker who keeps a friendly relationship with the addressee. In this context in the movie, the old man was informed that Johnny was angry with his girlfriend Angela. Hence, the old man was encouraging Johnny to treat Angela kindly. The old man did not tell Johnny directly to be kind with Angela, rather he utilised his good relationship with Johnny to achieve this goal. In this case, 
the use of the swearwords to primarily express the speech act of endearment was ascertained by the reaction of the addressee (Culpeper, Bousfield and Wichmann 2003). The perlocutionary force triggered by the articulation of these swearwords was a smile on the face of the addressee in the movie. Hence, despite the fact that the insulting swearword "fruitcake" was further emphasised by another swearword "fucking," the whole context of situation did not indicate the primary illocutionary force exhibiting a disparaging intent on the part of the speaker as it was uttered with a very low tone of voice coinciding with his intent to show intimacy and camaraderie. In this light, the addressee did not consider the swearwords offensive and, on this basis, he did not retaliate.

In the Arabic rendition, however, the swearword ahmaq [idiot], is abusive as it blatantly attacks the mental ability of the addressee and causes offense. It did not coincide with the harmonious relationship between an old man and a youth. Moreover, it was intensified by the vocative particle ayyuha (Lit. you!), to attract the attention of the addressee that he is the target of the illocutionary force of the speech act. Accordingly, the illocutionary force of the speech act accomplished by the swearword in the Arabic version became more forceful than that intended in the movie dialogue. This entails a change in the intended pragmatic function of the swearword in the source text whereby the social function the swearword expressed was skewed into an abusive function. In Arabic, the word ahmaq is negative, which creates contrast with the fact that the swearword in the source text is ecstatic with joy. Accordingly, the Arab viewers would question the incongruity between the relaxed atmosphere they see on the screen and the rudeness of the added insulting swearword ahmaq to the image. The inaccuracy in identifying the primary illocutionary force of the swearword in the source text might have led to a negative shift of this force in the target text, leading to a pragmatic failure. Example 8 further illustrates this shift.

Example 8 (HT):

You look like a gift-wrapped turd.

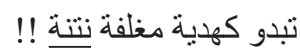
(tabdū kahadiyyatin mughalafatin natinatin) (Lit. You seem like a stinky wrapped gift.)

In example 8, the swearword "turd" was used by Sylvia, Mike's girlfriend to describe the way Jim looks in his new attire. Jim used to seek any opportunity to tease Sylvia to create banter. Sylvia believed that the main reason behind Mike's inability to find a job was the friendship he kept with Jim. In this context 
in the movie, while she was urging Mike to go and search for an employment, Jim appeared in his new attire to spoil her plan. The use of this swearword was meant to amuse the addressee because the primary illocutionary force of the speech act was not intended to be offensive since the addressee has a good friendly relationship with the speaker (Daly et al. 2004). This was reflected in his positive reaction to the utterance of the swearword in the movie, i.e., smiling. In the subtitles in Arabic, the word natinatin [stinky] was instead used as an equivalent for the swearword in the source text. When directly addressing the hearer, this word is considered an epithet and is meant to be humiliating and offensive because it is usually associated with the bad smell of filthy wastes. Accordingly, a change in the intended social pragmatic function of the swearword in the movie dialogue is reflected in the function of the rendered swearword, i.e., an abusive function in the subtitles. Here, the image on the screen conveys something different from what the Arab viewers observe than what is conveyed in the subtitle.

\section{Shift from the social functions in the source texts to the cathartic function in the target texts}

In such instances, the social pragmatic functions of the expressed swearwords in the movie dialogue were shifted to the cathartic functions in the subtitles. Although the result of this shift was less blatant than the shift into abusive functions, it entails a lack of accurate understanding of the intended uses of swearwords in the movies. Examples 9 and 10 illustrate this shift.

Example $9(\mathrm{AD})$ :

"What?" You deaf fuck. I said you're old.

$$
\begin{aligned}
& \text { ماذا ؟ ما الذي تقصده تبا؟؟ } \\
& \text { (madha? ma l-ladhī taqșuduhu, tabban?) } \\
& \text { (Lit. What? What do you mean, damn?) } \\
& \text { لقد قلت أنك عجوز } \\
& \text { (laqad qūltū anakah a'jūz) } \\
& \text { (Lit. I said you are old man.) }
\end{aligned}
$$

In example 9, the expressed swearwords "deaf" and "fuck" have the social functions of teasing the addressee to create laughter. In this context in the movie, the speaker, Johnny's father, and the addressee, an old man, were sitting in a restaurant and spending a friendly time with other members of the group. The main subject of their conversation was the old man's inability to have sex with women when they noticed the way he was looking at the waitress in the restaurant. In response to Johnny's father sexual insinuation in this regard, the 
old man uttered these swearwords. In such a context, the used swearwords were not intended to insult or disparage the addressee who was aware of the social function of these words and did not consider them as causing offense. In the subtitles, however, the use of the swearword tabban [May evil be fall] in Arabic resulted in a shift of the English original function. In Arabic, the word tabban is used to express stronger religious impulses such as going astray and be lost or destroyed (Ahmad et al. 2008). Therefore, the social function intended by the use of the swearwords in the movie dialogue was changed into a cathartic one whereby the speaker is portrayed as venting the inner feelings of dismay and frustration. Example 10 also illustrates this shift.

Example 10 (HT):

Oh, damn, dog, that shit was good, dude
اللعنة يا صاح هذا كان أداء رائعا

(al-la'nah yā șahi, hādhā kān adā'an rā'ian) (Lit. Damn, friend this was a marvelous performance.)

In example 10, the use of the swearword "damn" reflects a social pragmatic function, i.e., expressing the primary illocutionary force of intimacy between interlocutors via conveying Jim's admiration of his friend's (Mike) performance. Mike was making a fake phone call to Jim pretending to be a company manager who was telling Jim that his application for the job was successful. This was done to please Jim's girlfriend who was telling him in several occasions that he was no longer qualified for any job. Seeing Mike's excellent performance, Jim uttered this swearword. In the Arabic subtitles, the use of the swearword al-la'nah [damned], which is a literal translation of the English swearword "damn" resulted in a shift in the intended primary illocutionary force of the swearword. This shift stems from the fact that the word al-la'nah in Arabic expresses strong cathartic emotions of dismay and anguish.

\section{The Abusive Function of Swearwords in the Corpus}

Swearwords in the movies did not only express cathartic and social pragmatic functions, but a number of such words (22.75 percent) was used to express abusive pragmatic functions. The abusive function is the most venomous use of swearwords whereby the speaker intends to disparage and humiliate the addressee. This can be achieved via the most offensive words that are deemed appropriate to satisfy the speaker's purpose in that particular context of situation. 
In the Arabic subtitles, abusive pragmatic functions were mainly rendered into abusive functions with some instances of skewing to the cathartic function as shown in Table 1. The following subsections explain these renditions with illustrative examples.

\section{Abusive functions in source text maintained abusive in the subtitles}

When treating swearwords used to express abusive functions, maintaining similar abusive pragmatic functions of such words in the subtitles was the most common adopted translation pattern (Table 1). This entails a full understanding of the pragmatic functions of swearwords as used in their particular contexts of situation. Besides, this translation pattern reveals high felicity to the source text in an attempt to accurately reflect the atmosphere depicted in the movies to the Arab audiences. Examples 11 and 12 illustrate this translation behaviour.

Example $11(\mathrm{AD})$ :

Well, come on, you fucking pussy, do it!

هيا أيها الجبان إفعلها إفعلها (hayyā ayyuhā al-jabān ef'alhā, ef'alhā) (Lit. Come on, you coward, do it do it.)

In example 11, Jake used the swearwords "fucking pussy" with the intent to directly insult Johnny. In this context, Jake was in a brawl with Johnny because the former was unable to pay Johnny back his money. When Johnny was defeated, he pointed a gun at Jake. Reacting to this, Jake used the abusive swearwords as disparaging and humiliating verbal attacks since they severely criticise Johnny's masculinity and physical ability. In other words, Jake used the swearword "pussy," which is usually used for females with the primary illocutionary force to adversely wound Johnny. To further strengthen his attack, Jake used another swearword "fucking" as an emphatic intensifier. Moreover, he used the vocative "you" to remove any possible equivocation of who was intended by these swearwords. Hence, the abusive pragmatic function of the swearwords becomes evident. Similarly, in the subtitles, the word jaban [coward], was used to convey this pragmatic function. On its part, this word is highly abusive to an Arab male as it degrades his masculinity. The speaker's disparaging intent was emphasised by two other particles; the repetition of the word ef'alha [do it] and the vocative ayyuha $\bar{a}$ [you]. Hence, a similar abusive pragmatic function was achieved in the subtitles although the sexual overtone of the word "fucking" was missing because of the shift to another semantic field of swearwords in the target text. This shift is also illustrated in Example 12. 
Example $12(\mathrm{HT})$ :

Fucking dick.

$$
\begin{array}{r}
\frac{1}{\text { اللعبين الأحمق }} \\
\text { (al-la'in al-ahmaq) } \\
\text { (Lit.Damned idiot.) }
\end{array}
$$

Example 12 is taken from a scene in the movie in which Jim was informed that he was illegible for the job he applied for. His friend Mike tried to calm him down and find justification for the rejection of the application. Jim was not satisfied with Mike's suggestion and used the swearwords "fucking dick" to express an abusive pragmatic function by directly addressing Mike. The swearword "dick" was used with the primary intent to insult Mike's mental ability and was further emphasised by the intensifying word "fucking." In the subtitles, a similar abusive pragmatic function was conveyed to the Arab audience via the use of two abusive swearwords al-la 'in [damned] and ahmaq [idiot]. The word ahmaq expresses the same pragmatic function as the word "dick" in this context since it insults the mental ability of the addressee and was emphasised by the word al-la' $i n$. Hence, the translation is highly felicitous to the source text regarding the intended pragmatic function of the swearwords though via the use of swearwords from another field in the target text.

\section{Shift from abusive to cathartic functions of swearwords in the subtitles}

There were also some instances in which the abusive pragmatic functions intended by the use of swearwords in the source texts were shifted to cathartic in the target texts via the transferred word or phrase in the subtitles. This suggests the use of equivalents that do not exactly convey the same primary illocutionary force intended by the English original. Consequently, the intended communicative force of the swearwords was attenuated in the target texts. This is evident in Examples 13 and 14.

Example 13 (AD):

- Shut your fucking mouth!

- We're not gonna do this?

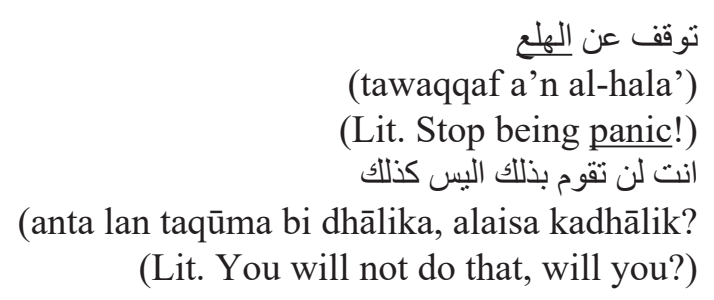


In example 13, the intended primary pragmatic function expressed by the swearword "fucking" is abusive as it directly insults the addressee. The context in the movie in which this swearword was uttered was so critical whereby a decision to kill a small boy (Zack) was about to be taken by Elvis. Preceding this scene, there was a certain urging beseech by the addressee (Frank) to stop the murder. Elvis uttered this insulting swearword to be despicable of Frank's behaviour, which was persistently urging in nature. This abusive function as expressed by the swearword was shifted into a cathartic one in the subtitles via the use of the swearword al-hala' [being panic]. Thus, the hostile intent in the source text was changed into a hortatory one in the subtitles. As a result, the fierce and insulting tone of voice in this scene was attenuated in the subtitles, leading to a negative shift of the illocutionary force of the swearword and causing a lower degree of pragmatic intensity in the target text (RodríguezMedina 2015). Consider also Example 14.

Example $14(\mathrm{HT})$ :

I'm not your fucking puppet, Sylvia

أنا لست لعبة بيديك يا "سيلفيا" (anā lastu lu'batan biyadaiki, yā silvia) (Lit. I am not a toy in your hands, Sylvia.)

In example 14, the abusive primary pragmatic function was expressed by the swearwords "fucking puppet," which were meant to show contempt of the addressee. In this context in the movie, Mike intended to express his revolt against his girlfriend Sylvia's attempt to dominate him. In this encounter, Mike gave his friends a promise to join them in a trip to Mexico. Sylvia tried to prevent him from travelling and go seeking for a job instead. Finding himself embarrassed in front of his friends, Mike uttered this swearing expression. In the subtitles, however, this pragmatic function of the swearword in the source text was changed to a cathartic one via the rendering of the English swearword by the word lu'batan [toy] and the omission of the intensifying vulgar word "fucking." Thus, the fierce and reproaching intent of the speaker expressed through using the swearword in this context in the movie was changed into a simple flat expression of cathartic inner feelings in the subtitles. The result of such a skewing of the intended abusive pragmatic function of the swearing act is an inaccurate portrayal of the relationship between the characters in the movie to the target audiences. 


\section{CONCLUSION}

This study has attempted a qualitative analysis of the translation behaviour of Arab amateur subtitlers, vis-à-vis the retention of the pragmatic functions expressed by swearwords in the movies when subtitled into Arabic. Based on the results of the analysis of the pragmatic functions expressed through the use of various types of swearwords in both sub-corpora, the following conclusions can be highlighted:

There was a great deal of incongruity in the pragmatic functions expressed by the swearwords in the movie scripts in comparison with those rendered in the subtitles. As a result of this, although a similar dominance of the cathartic functions was maintained in the subtitles as those in the movies, several instances of cathartic swearing were changed to express abusive functions or rendered into cathartic functions with less swearing communicative force. Moreover, the numerous instances of social functions expressed by the swearwords in the movies were almost completely changed to express either abusive or cathartic functions in the subtitled versions. Finally, the abusive functions were increased in the subtitles due to the resulting changes in the majority of the social functions and certain cathartic functions to abusive ones though with skewing of some abusive instances to catharsis.

The changes indicated above resulted in a significant variation in the distribution of the pragmatic functions expressed by the swearwords in the movies compared to those in the subtitles. That is to say, while in the movie dialogues the cathartic pragmatic functions had the greatest number of expressed pragmatic functions followed by the social and then the abusive functions, the cathartic functions in the subtitles were followed by the abusive functions and the social pragmatic functions were the least conveyed to the target audience. In addition, there was an inconsistency in the direction of changes of the expressed pragmatic functions. To reiterate, while there were several instances of skewing to the abusive or cathartic functions within the cathartic and abusive functions of swearwords rendered into Arabic, no instance of change from these functions to the social functions was observed.

The state of affairs described in the above two paragraphs reflects a lack, on the part of amateur subtitlers, of a meticulous pragmatic analysis of the contextual cues in the situations in which the swearwords were employed to express certain intended pragmatic functions. Thus, having the knowledge of pragmatics helps subtitlers signal the relationship between interlocutors engaged in a conversational event and the intended illocutionary force behind the use of swearwords. Moreover, it helps in signalling the reaction of the 
addressee or the perlocutionary force towards the use of such words and accurately identifying their pragmatic functions. The lack of such an analysis may be attributed to the low pragmatic competence of amateur subtitlers ( $\mathrm{La}$ Forge and Tonin 2014).

The consequences of the lack of pragmatic analysis of the functions expressed by swearwords in the source texts were manifested either in the way interpersonal relations between characters in the movies were reflected to the Arab audiences or in the portrayal of the characters' sociocultural background. They were also manifested in the expression of each character's personal inner feelings. Generally speaking, they contributed into making the subtitled versions of the movies harsher and more offensive to the Arab audiences, particularly when the changes from the social to abusive or cathartic functions and the increase in the instances of abusive swearing are considered. The increase in the number of abusive functions in the subtitles led to an increase in the communicative effect of swearwords not as intended in the source texts and it attracted more attention to these words in the target texts.

The findings of the study suggest that swearwords can cause serious translation problems to subtitlers, particularly when rendering a text from an open culture to a conservative one. Since this study was confined to the amateur subtitling of swearwords in selected American crime drama movies into Arabic, future studies could focus on comparisons between professional and amateur subtitling of swearwords in similar movies and/or other types of movies. Further studies could also identify the translation strategies adopted by each group of subtitlers and the effect of each strategy on preserving the source text intended pragmatic functions of swearwords in the target text.

\section{NOTES}

Abed Shahooth Khalaf is an Associate Professor at the College of Education for Humanities, University of Anbar, Iraq. He obtained his MA in Translation from Yarmouk University, Jordan in 2000 and his $\mathrm{PhD}$ in Audiovisual Translation from Universiti Putra Malaysia, Malaysia in 2016. He has published several journal articles in the fields of translation studies, applied linguistics, semantics and pragmatics, and has participated in a number of international conferences, mainly, as paper presenter. His research interests and publications are in the areas of audiovisual translation, translation problems and pragmatics.

** Sabariah Md. Rashid is a senior lecturer at the Department of English, Faculty of Modern Languages and Communication, Universiti Putra Malaysia (UPM). She obtained her PhD from Universiti Kebangsaan Malaysia and Master's degree from University of Reading, United Kingdom, and Bachelor's degree from University of 
Essex, United Kingdom. She has taught a variety of linguistic and applied linguistic courses at undergraduate and postgraduate levels, and has successfully graduated various $\mathrm{PhD}$ and Master students in the field of English Studies and Translation and Interpretation. Her research interests and publications are in the areas of applied linguistics, language testing, cognitive semantics, pragmatics, and semantic and pragmatic analyses in translation. She has also participated in conferences, mainly, as paper presenter at national and international conferences. Professionally, she has been a trainer for various professional English programmes and a consultant, test developer and rater in national English language testing projects in the aviation context.

\section{REFERENCES}

Ahmad, N. S. et al. 2008. Al-Mu'jam al-wasit. Beirut: Dar Ihya' al-Turath al-Arabi.

Al-Khatib, M. A. 1995. A sociolinguistic view of linguistic taboo in Jordanian Arabic. Journal of Multilingual \& Multicultural Development 16 (6): 443-457, https://doi. org/10.1080/01434632.1995.9994617.

Alpha Dog (AD). 2006a. Arabic subtitles. http://www.subscene.com (accessed 27 April 2015).

2006b. English scripts. http://www.opensubtitles.org/en/search (accessed 27 April 2015).

Ameri, S. and Ghazizadeh, K. 2015. A norm-based analysis of swearing rendition in professional dubbing and non-professional subtitling from English into Persian. Iranian Journal of Research in English Language Teaching 2: 78-96.

Andersson, L. G. and Trudgill, P. 1990. Bad language. Oxford: Basil Blackwell.

Austin, J. L. 1962. How to do things with words. Oxford: Oxford University Press.

Bogucki, Ł. 2009. Amateur subtitling on the Internet. In Audiovisual translation: Language transfer on screen, eds. Díaz-Cintas, J. and Anderman, G., 49-57. London: Palgrave Macmillan, https://doi.org/10.1057/9780230234581_4.

Bucaria, C. 2009. Translation and censorship on Italian TV: An inevitable love affair? Vial-vigo International Journal of Applied Linguistics 6: 13-32.

Casarini, A. (2014). The perception of American adolescent culture through the dubbing and fansubbing of a selection of US teen series from 1990 to 2013. PhD diss., Università di Bologna, Italy.

Chesterman, A. 1997. Memes of translation: The spread of ideas in translation theory, vol. 22. Amsterdam: John Benjamins Publishing.

Culpeper, J., Bousfield, D. and Wichmann, A. 2003. Impoliteness revisited: With special reference to dynamic and prosodic aspects. Journal of Pragmatics 35: 1545-1579, https://doi.10.1016/S0378-2166(02)00118-2.

Cutting, J. 2002. Pragmatics and discourse: A resource book for students. London: Routledge.

Daly, N. et al. 2004. Expletives as solidarity signals in FTAs on the factory floor. Journal of Pragmatics 36: 945-964, https://doi.10.1016/j.pragma.2003.12.004.

Dewan Bahasa dan Pustaka. 2008. Pedoman transliterasi huruf arab ke huruf rumi. Kuala Lumpur: Dewan Bahasa dan Pustaka. 
Díaz-Cintas, J. 2005. Back to the future in subtitling. Paper presented at the EU-HighLevel Scientific Conference Series, MuTra 2005 - Challenges of Multidimensional Translation. https://euroconferences.info/proceedings/2005_Proceedings/2005_ DiazCintas_Jorge.pdf (accessed 7 April 2014).

Diaz-Cintas, J. and Remael, A. 2007. Audiovisual translation: Subtitling. Manchester: St. Jerome Publishing.

Diaz-Cintas, J. and Sánchez, P. M. 2006. Fansubs: Audiovisual translation in an amateur environment. The Journal of Specialised Translation 6: 37-52.

Fernandez-Costales, A. 2012. Collaborative translation revisited: Exploring the rationale and the motivation for volunteer translation. Forum 10: 115-142, https://doi. org/10.1075/forum.10.1.06fer.

Gamal, M. Y. (2008). Egypt's audiovisual translation scene. Arab Media \& Society 5: 1-15.

García-Manchón, P. 2013. A corpus-based analysis of swear word translation in DVD subtitles and Internet fansubs. Unpublished MA diss., Universidad Complutense, Spain.

Gottlieb, H. 1998. "Subtitling." In Routledge encyclopedia of translation studies, ed. Baker, M., 244-248. London: Routledge.

2001. Texts, translation and subtitling - In theory, and in Denmark. In Translators asnd translations, eds. Holmboe, H. and Isager, S., 149-192. Aarhus, Denmark: Aarhus University Press.

. 2004. Subtitles and international anglification. Nordic Journal of English Studies 3 (1): 219-230.

Greenall, A. K. 2011. The non-translation of swearing in subtitling: Loss of social implicature. In Audiovisual translation in close-up: Practical and theoretical approaches, eds. Şerban, A., Matamala, A. and Lavaur, J-M., 45-60. Bern: Switzerland International Academic Publishers.

Guardini, P. 1998. Decision-making in subtitling. Perspectives: Studies in Translatology 6: 91-112, https://doi.org/10.1080/0907676X.1998.9961326.

Halliday, M. A. K. 2004. An introduction to functional grammar, 3rd ed. Oxford: Oxford University Press.

Han, C. and Wang, K. 2014. Subtitling swearwords in reality TV series from English into Chinese: A corpus-based study of The Family. Translation and Interpreting 6: 1-17.

Harsh Times (HT). 2005a. Arabic subtitles. http://www.subscene.com (accessed 14 December 2014).

2005b. English scripts. http://www.opensubtitles.org/en/search (accessed 14 December 2014).

Hjort, M. 2009. Swearwords in subtitles. A balancing act. InTRAlinea Special Issue: The Translation of Dialects in Multimedia. http://www.intralinea.org/archive/ article/1718 (accessed 10 January 2017).

House, J. 1981. A model for translation quality assessment. Berlin: Gunter Narr Verlang Tubingen.

Ivarsson, J. and Carroll, M. 1998. Subtitling. London: TransEdit.

James, C. 1998. Errors in language learning and use: Exploring error analysis. London: Routledge. 
Kovacic, I. 1995. Reinforcing or changing norms in subtitling. In Teaching translation and interpreting 3, eds. Dollerup, C. and Appel, V., 105-109. Amsterdam: Benjamins Publishing Company.

La Forge, F. and Tonin, R. 2014. In a quiet weekend of fear, an exorcist flew over the nest: A case study of the intertexual references in subtitling and dubbing Italian and Spanish series supernatural. InTRAlinea 16: 1-13.

Lee, H.-K. 2011. Participatory media fandom: A case study of anime fansubbing. Media, Culture \& Society 33: 1131-1147, https://doi.org/10.1177/0163443711418271.

Lie, S. 2013. Translate this, motherfucker! A contrastive study on the subtitling of taboo words. PhD diss., Universiteteti Oslo, Norway.

Ljung, M. 2009. The functions of expletive interjections in spoken English. In Corpus linguistics: Refinements and reassessments, eds. Renouf, A. and Kehoe, A., 155-171. Amsterdam: Rodopi.

Massidda, S. 2012. The italian fansubbing phenomenon. PhD diss., Universita degli Studi di Sassari, Italy.

Mazid, B. 2006. Arabic subtitles on English movies: Some linguistic, ideological and pedagogic issues. International Journal of Arabic-English Studies (IJAES) 7: 81100.

McNeill, D. 2006. Gesture: A psycholinguistic approach. The Encyclopedia of Language and Linguistics 58-66.

Moad, Q. 2011. List of movies with the most audible uses of "fuck." http://www.listology. com/quinton-moad/list/list-movies-most-audible-uses-word-fuck (accessed 1 January 2015).

Mubenga, K. S. 2010. Investigating norms in interlingual subtitling: A systemic functional perspective. Perspectives: Studies in Translatology 18: 251-274, https://doi.org/10 .1080/0907676X.2010.482993.

Nornes, A. M. 1999. For an abusive subtitling. Film Quarterly 52 (3): 17-34, https://doi.org/10.2307/1213822.

Orrego-Carmona, D. 2012. Internal structures and workflows in collaborative subtitling. Paper presented at the First International Conference on Non-professional Interpreting and Translation, 17-19 May 2012, Università di Bologna, Forlì.

. 2014. Where is the audience? Testing the audience reception of non-professional subtitling. Translation Research Projects 5: 77-92. http://isg.urv.es/publicity/isg/ publications/trp_5_2014/index.htm.

2015. The reception of (non) professional subtitling. PhD diss., Universitat Rovira I Virgili, Spain.

Parini, I. 2013. Taboo and translation in audiovisual works. In Translation right or wrong, eds. Belenguar, S. B., Chuilleanain, E., N. and Cuilleanain, C. O., 149-161. Dublin: Four Court Press.

Pedersen, J. 2008. High felicity: A speech act approach to quality assessment in subtitling. In Between text and image: Updating research in screen translation, eds. Delia, C., Heiss, C. and Bucaria, C. 101-116. Amsterdam: John Benjamins.

Perez-Gonzalez, L. 2012. Amateur subtitling and the pragmatics of spectatorial subjectivity. Language and Intercultural Communication 12: 335-352, https://doi.org/10.1080/14708477.2012.722100. 
Renwick, O. 2012. Subtitling obscenities. www.oliverrenwick.com/2012/06/11/subtitling obscenities (accessed 10 Jan 2017).

Rodríguez-Medina, M. J. 2015. Appraising the translation of dysphemisms. Insights into the Spanish crime film dubbese. InTRAlinea: Online Translation Journal 17.

Sajna, M. 2013. Amateur subtitling - Selected problems and solutions. T21N-Translation in Transition 3: 1-18.

Searle, J. R. 1976. A classification of illocutionary acts. Language in Society 5: 1-23.

Tapscott, D. and Williams, A. 2006. Wikinomics: How mass communication changes everything. London: Penguin Group.

Tian, Y. 2011. Fansub cyber culture in China. PhD diss., Georgetown University, United States.

Titford, C. 1982. Sub-titling: Constrained translation. Lebende Sprachen. Zeitschrift für Fremde Sprachen in Wissenschaft und Praxis Berlin 27: 113-116.

Venuti, L. 1995. The translator's invisibility: A history of translation. London: Routledge.

Verschueren, J. 1999. Understanding pragmatics. Chicago: Oxford University Press.

Wajnryb, R. 2005. Expletive deleted: A good look at bad language. London: Free Press.

Wilcock, S. 2013. A comparative analysis of fansubbing and professional DVD subtitling. $\mathrm{PhD}$ diss., University of Johannesburg, South Africa.

Yule, G. 1996. Pragmatics. Oxford: Oxford University Press.

Zauberga, I. 1994. Pragmatic aspects of the translation of slang and four-letter words. Perspectives: Studies in Translatology 2: 137-145, https://doi.org/10.1080/090767 6X.1994.9961231. 